\title{
Pawn and King Play: A Stalemate on Rural Emergency Medicine Staffing
}

\author{
W. Anthony Gerard, MD
}

(J Am Board Fam Med 2019;32:292-294.)

"It is certain, whether we be first rates, or lowly recipients of the Queen, at the end of the game, 'the King and the Pawn both go into the bag." Old Proverb from The Westminster Articles: A Monthly Journal of Chess, 1873.

In the article titled, Family Physicians Make Significant Contributions to the Rural Emergency Care and Urban Urgent Care Workforce, ${ }^{1}$ Peterson and colleagues show that "Family physicians (FPs) are likely to continue to be the backbone of emergency care in rural America." The authors provide data and compelling arguments for this claim. But will this help "move the pawn to the end of the board?” Rural emergency department (ED) workforce issues should not be subject to this game of chess between emergency medicine (EM) and family medicine (FM).

The authors demonstrate a sharp increase in the proportion of American Board of Family Medicine (ABFM) -certified FPs working primarily in rural EDs. They show that up to $8.5 \%$ of FPs work full time as emergency physicians (EPs) in the most rural EDs. There are about 90,000 diplomates of the ABFM, which translates to an estimated $7600 \mathrm{FPs}$ working full time in these "frontier" emergency departments. Many more work part time covering local EDs. These data clearly show that "FPs are likely to be likely to continue to be the backbone of emergency care in rural America."

Peterson's study also emphasizes the important role that FM has in providing quality urgent care (UC). FM already provides the lion's share of the workforce in urgent care, and in this study, the

Funding: none.

Conflict of interest: none declared.

Corresponding author: W. Anthony Gerard, MD, Emergency Department, Lebanon VA Medical Center, 1700 S Lincoln Ave, Lebanon, PA, 17042 (E-mail: wanthonygerard@gmail.com). percentage of FP's working in UC went up. FM's strength in providing UC is well known, so turf wars between FM and EM are rare in UC.

But the history of "turf wars" in EM dates back to the beginning of our specialty, and has led to a "game of chess" in rural health policy, in which EM has controlled the board. FM has not "sacrificed it is pawn," but this history of competition has led to a stalemate. ${ }^{2}$

We have arrived at a stalemate as the health policy debate on rural EM has been "specialty centric," not "patient centric." Collaboration-not competition-is needed to solve rural ED workforce issues and improve patient care. Health policy recommendations have emphasized the importance of a partnership between specialties to solve rural $\mathrm{EM}$ issue, but due to the politics of medicine, these recommendations have largely been ignored. ${ }^{3}$

In 2006, the Institute of Medicine (now the National Academy of Medicine) issued a report on EM. ${ }^{4}$ This called for "more collaborative efforts between specialties... [because] family physicians are an essential component of the ED workforce... with a high level of competency in emergency care through a combination of residency and postresidency education, directed skills training, and onthe-job experience." Other authors have repeated this theme $\mathrm{e}^{5-7}$ but FM and EM continue to move chess pieces instead of collaborating.

The reasons for EM's "specialty-centric" focus were understandable a few decades ago, when the certification debate was threatening to the EM scope of practice. ${ }^{8}$ But EM is almost 60 years old, and it is time to move past our adolescent angst about our scope of practice. Residency-trained emergency physicians lead the specialty, and the academic emphasis of EM has greatly improved the quality of care in EDs. Emergency medicine is now one of the most sought-after specialties. We are no longer considered just "ER docs," as evidenced by 
our vital role in the health care system and recognition by other specialties.

But in rural and community hospitals across the country, FPs are part of this workforce (even though they may be lowly pawns.). In critical access hospitals, FPs are likely to be the only physician specialty. "The King may be the most important piece on the chess board, but there would be no game of chess without the pawns."

Emergency medicine and FM are developmentally linked, making it ironic that we have not cooperated on rural EM workforce issues. The pioneers of EM included FPs who helped develop the specialty. They championed its cause with the American Board of Medical Specialties because they saw the need for better-trained physicians to staff the "ERs of America." In these early days, the leaders of both specialties "envisioned extensive cooperative efforts...."9

The authors quote from an overly optimistic study of the EM workforce, ${ }^{10}$ which predicts that "within 5 to 10 years there will be enough boardcertified EPs to provide care to all patients." This study, published in a journal sponsored by the American Academy of Emergency Medicine (AAEM), buttresses the academic EM perspective that the entire EM workforce should be residency-trained EPs (this is one of the reasons AAEM was founded ${ }^{11}$ ). But several other workforce studies show that this is a dream that is unlikely to ever become a reality, especially in rural areas. ${ }^{12,13}$ This argument also furthers the debate between physician specialties instead of focusing on what is best for patients in all parts of America.

In the most rural EDs, the likelihood of being seen by an American Board of Emergency Medicine (ABEM) board-certified EP decreases 5-fold compared with larger hospitals, and patients are seven times more likely to be treated by a FP. ${ }^{14}$ In Iowa, almost a quarter of EDs were staffed exclusively by FPs, and only $12 \%$ of EDs were staffed by residency-trained EPs. ${ }^{15,16}$ Peterson et al ${ }^{1}$ correctly conclude that " low-volume rural EDs will likely remain highly dependent on broad-scope FPs to meet their staffing needs."

FPs who provide emergency care do not want to replace EPs, and depend on the leadership of ABEM physicians, but are a logical choice to supplement the EM workforce. The American Academy of Family Physicians (AAFP) Position Statement makes this clear: "Family physicians are trained in the breadth of medical care, and as such are qualified to provide emergency care in a variety of settings. In rural and remote settings, family physicians are particularly qualified to provide emergency care." ${ }^{17}$ Since we are developmentally and intrinsically linked, EM and FM should be collaborating to solve rural EM issues, not continue the stalemate. Competition between EM and FM should be replaced with cooperation. The chess game should be considered a draw.

In 2008, the Institute for Health care Improvement introduced a program intended to improve health care in the US, titled, The Triple Aim. ${ }^{18}$ The program was intended to improve population health while also improving the patient experience, and simultaneously reducing costs. This health care transformation has become widely used-or at least widely referenced-as hospitals and health systems have strived to improve patient outcomes. The concept of the Triple Aim has now been adopted as part of the national strategy for US health care, and should be considered for rural EDs.

Rural EM needs to have this kind of approach, since neither EM or FM can improve rural health care working alone. The Triple Aim requires an "integrator," which is an entity that "links health care organizations and induce coordinative behaviors." The Triple Aim also requires "disruptive innovations" to barriers such as "physician centric care." Under this new model, primary care and EM would collaborate to provide rural emergency care and achieve gains on all 3 aims: care, cost, and health. But, as the authors clearly state, the "barriers (to this type of innovation) are not technical, they are political."

There are reasons for hope. Academic EM leaders from several universities recently published an excellent article on the EM workforce." ${ }^{19}$ According to the lead author, "more than one third of ED clinicians are someone other than an emergency physician.... [The] EM workforce is broad based with a variety of ambulatory care skill sets in addition to EM experience."

An innovative idea for improving rural health in EDs was recently proposed by Greenwood-Ericsson et $\mathrm{al}^{20}$ They propose a "new health-care delivery model for rural population health based on a partnership between EM and primary care." Rural EDs would become "a collaborative domain of both emergency and primary care." Implicit in this is a recognition of the important role FPs play in rural ED's, 
where a "mixed staffing model is common... providers trained in both EM and primary care."

The unofficial elegist of EM, Dr Edwin Leap (who is a rural EP), writes, "We are divided between rural and urban, and there are significant problems in that chasm. Physicians in urban teaching centers sometimes have little knowledge of the stark limitations of the rural setting when we call for help or transfers. 'You do not have a surgeon? You do not have an ICU [intensive care unit]?' And rural physicians often forget that even the big house eventually reaches capacity and cannot take transfers; the presence of a large center (or a helicopter) is no excuse for sloppy care on the outside.... Never forget that we can serve as a model for unity, a model for the greatness of all free people, when we do our jobs well and do them together for the good of others." ${ }^{21}$

To see this article online, please go to: http://jabfm.org/content/ 32/3/292.full.

\section{References}

1. Peterson LE, Puffer JC, Nasim U, Petterson S, Newton WP. Family physicians' contributions to rural emergency care and urban urgent care. J Am Board Fam Med 2019;32:295-296.

2. Gerard W, Anthony MD, Bullock K, Staufffer A. Focus on patient care, not turf wars. Emerg Med News 2010;32:8-18.

3. Banks GC, Gerard Aw, Yu K, Bullock KA. Family physicians play integral role in emergency medicine. Ann Fam Med 2017;15:84-6.

4. Institute of Medicine. Hospital-based emergency care: at the breaking point. Available from: http://www. nationalacademies.org/hmd/Reports/2006/HospitalBased-Emergency-Care-At-the-Breaking-Point.aspx. Accessed May 22, 2017.

5. Gerard WA, Pugno PA, Bullock K, Greig D. Rural emergency medicine rotations: could family practice (ABFM) faculty supplement ABEM faculty? Ann Emerg Med 2013;62:645-6.

6. Gerard W, Pugno PA, Rodney WM. Viewpoint: An unfulfilled mandate: FPs vital to the EM workforce. Emerg Med News 2016;38:3-4.

7. Rodney WM, Crown LA, Hahn R, Martin J. Enhancing the family medicine curriculum in de- liveries and emergency medicine as a way of developing a rural teaching site. Fam Med 1998;30: 712-9.

8. McKenna M. IOM Report Ignites New Debate on Who Should Practice Emergency Medicine, Annals of EM, 2007;614-7.

9. Dervin JV. Emergency medicine and family practice-Room for both. JACEP 1976;5:909-10.

10. Reiter M, Wen LS, Allen BW. The emergency medicine workforce: Profile and projections. J Emerg Med 2016;50:690-3.

11. McNamara, R. The Founding and Flowering of AAEM. Available from: https://www.aaem.org/UserFiles/FoundersForumMarApr13_v1.pdf.

12. Ginde AA, Sullivan AF, Camargo CA Jr. National study of the emergency physician workforce, 2008. Ann Emerg Med 2009;54:349-59.

13. Counselman FL, Marco CA, Patrick VC, et al. A study of the workforce in emergency medicine: 2007. Am J Emerg Med 2009;27:691-700.

14. Peterson LE, Dodoo M, Bennett KJ, Bazemore A, Phillips RL Jr. Nonemergency medicine-trained physician coverage in rural emergency departments. J Rural Health 2008;24:183-8.

15. House H, Young R, DeRoo E. Penetration of board certified emergency physicians into rural emergency departments in Iowa. Ann Emerg Med 2009;54:S64.

16. Groth H, House H, Overton R, Deroo E. Boardcertified emergency physicians comprise a minority of the emergency department workforce in Iowa. West J Emerg Med 2013;14:186-90.

17. American Academy of Family Physicians (AAFP). Critical challenges for family medicine: Delivering emergency medical care, equipping family physicians for the 21st century? [Position Paper]. Available from: http://www.aafp.org/online/en/home/policy/ policies/e/emposition.html.

18. Berwick DM, Nolan TW. The Triple Aim: care, health, and cost. Health Aff (Millwood). 2008;27: 759-69.

19. Hall MK, Burns K, Carius M, Erickson M, Hall J, Venkatesh A. State of the National Emergency Department Workforce: Who Provides Care Where? Ann Emerg Med 2018;72:302-7.

20. Greenwood-Ericksen MB, Tipirneni R, Abir M. An emergency medicine-primary care partnership to improve rural population health: expanding the role of emergency medicine. Ann Emerg Med 2017;70:640-7.

21. Leap E. A model for unity and greatness. Emerg Med News 2017;39:16. 